\title{
IMPLEMENTATION OF BUSINESS INTELLIGENCE IN AN IT ORGANIZATION - THE CONCEPT OF AN EVALUATION MODEL
}

\author{
Tomasz SITEK*, Michał LITKA** \\ Gdansk University of Technology, Gdańsk, Poland \\ *e-mail: tomasz.sitek@zie.pg.gda.pl \\ **e-mail: litka.michal@gmail.com
}

\begin{abstract}
This paper presents the issue of assessing the validity and effectiveness of implementing a Business Intelligence system in an IT Support Organization. This entity provides IT services to external clients involving, in particular, the storage and processing of large amounts of data. The vast amount of realized projects and also incidents reported in connection with those projects prevented effective decisions from being made without the support of dedicated technologies. The authors present the problems encountered by the studied entity and describe the tool that was selected to improve the situation. The aim of this study is to measure and describe the key processes in the organization on the basis of prepared aggregated measures, first prior to the implementation of the BI system and then a year after its implementation. The evaluation model developed by the authors allowed the assessment of the key aspects of the company's operation over 2 years. It thus helped decision makers to establish whether the decision to implement the Business Intelligence system was correct or not.
\end{abstract}

Keywords: Business Intelligence, IT support organization, decision-making, evaluation model.

Decision-making issues in IT organizations

Over the years, the amount of data needed by organizations for their proper functioning has grown considerably. The history of portable data storage devices is an excellent example of this. At the beginning of the 1990 s, a floppy disk with $<1.5$ MB capacity was sufficient for most needs; at times, it was necessary to use several disks. A few years later, the CD appeared, which at that time had an unimaginable capacity of 700 MB. But this also proved to be too little - another leap forward in the form of DVDs increased the available portable storage capacity by more than six times. Today's portable memory sticks are smaller than a matchbox, and yet allow a few (or a few dozen) times more data to be stored than a DVD.

With the increase of available disk space, data management skills have been lost - why would anyone bother about three identical copies of the same file if hundreds of gigabytes of free space were still available? For home users, this is not such a big problem. However, what happens when the same approach is carried out by a company that uses hundreds of computers? The demand for available memory is growing rapidly and the cost of infrastructure is rising with it. It should also be noted that although data are collected for a specific purpose, obtaining the necessary information from it is often very difficult. When it comes to taking strategic decisions, it is then necessary to manu- ally analyze multiple sets of data (files) and draw conclusions from them. Such a painstaking search rarely gives measurable results.

In principle, the decision-making process is performed in several steps: defining the problem, examining the options, predicting the consequences and choosing the optimal variant [1]. The first one is often problematic, especially in the aforementioned case of data excess. It often transpires that the data are scattered. It can happen that the data from one branch is much older than the data from another branch, which makes taking a joint decision for the entire organization impossible. It may also be the case that the data from several sources is redundant, which leads to the situation where a manager is overwhelmed with data from among which it is hard to select the really important information. The organization can then quickly experience the so-called domino effect. Excess data complicate its analysis, and this less effective analysis affects the formation of available options to choose from. On the basis of incorrectly analyzed, incomplete or simply incorrect information, predicting the consequences of a choice is difficult, to say the least. In such circumstances, an option that appears to be optimal is not so in reality [2].

Paradoxically, in this day and age when a great deal of work has been computerized, decision-making is not easier than it was in the past. 
In most organizations, including IT organizations, the decision-making process is accompanied by a number of problems [3]:

- excess or insufficiency of data,

- inability to interpret data and transform it into information,

- inaccuracies of data (information),

- dispersed data,

- free access to data,

- difficulties with the aggregation of data and information,

- difficulties associated with reducing uncertainty.

There are IT technologies that support the decisionmaking process [4]. This support involves solving or simplifying the problems that occur in the process. They allow faster data access, aggregation and analysis. A huge amount of dispersed information from different parts of the company can be aggregated in one place, while maintaining its readability and giving it an ordered structure. These technologies also allow for the analysis of the information and for the creation of reports, thanks to which the issue of uncertainty in the decision-making process is minimized. Thus, the risk of making a bad decision is reduced, and the probability of making the right one is increased. The tools we are referring to here are defined as Business Intelligence.

The implementation of a Business Intelligence technology is a significant cost to the organization. The question is whether the cost can be justified in a quantitative manner? Is it possible to assess the effects of this decision after a system of this class is introduced? Our experience shows that this is a problem for many organizations. The assessment of the situation after the implementation of the system is usually of a qualitative nature and, as it is based on the subjective feelings of the users, can be radically different depending on their position, on the scope of their operations and on the changes which affected them directly [5].

Having obtained very detailed quantitative data collected in the organization prior to and after the implementation of a Business Intelligence system, the authors analyzed the data and established that it is the basis for the construction of an evaluation model to assess the validity of this implementation. This article thus presents a test organization, the indicators developed for measuring key aspects of the business and presents a method for the quantitative evaluation of the effectiveness of such an implementation.

\section{Business Intelligence as a method for supporting the decision-making process}

Business Intelligence, also referred to as BI, is a term, which can be defined in many ways. This paper follows the definition developed by Gartner - a consulting firm specializing in the strategic use of technology [6]. Gartner defines BI as "is an umbrella term that includes the applications, infrastructure and tools, and best practices that enable access to and analysis of information to improve and optimize decisions and performance" [7].

A typical BI system architecture is composed of several elements. The heart of this system is formed by data warehouses, namely databases focused on dealing with analytical queries. Data are transferred to warehouses from several sources: systems such as ERP, CRM, SCM, Call Centers and others, with the help of ETL processes (ETL stands for Extract, Transform, Load) [8]. These processes integrate data from various systems into a single unified model, the so-called multidimensional model. Then, data from warehouses are often used in analytical query processing engines (OLAP, Online Analytical Processing), which allow for quick analyses at different levels and with different sets of questions, sometimes quite abstract ones.

The user can then access the results of these analyses via business and analytical tools. These tools present information as a series of reports and analyses - very often this is achieved via the so-called managerial dashboards. Of course, these applications can provide information in other forms, such as spreadsheets or PDF documents. It is often possible to deliver reports to the mailboxes of selected users, whether as part of the normal course of monitoring, or in the event of an emergency. Typically, BI systems work on online platforms, allowing business users to access reports and analyses through a web browser. The aim is to facilitate access to information regardless of the location of the person who is trying to obtain it. Therefore, the BI system consists of data sources which, due to the presence of ETL processes, enter the data warehouses and go further to analytical and reporting applications. Schematically, the idea of BI can be illustrated as in Figure 1. 


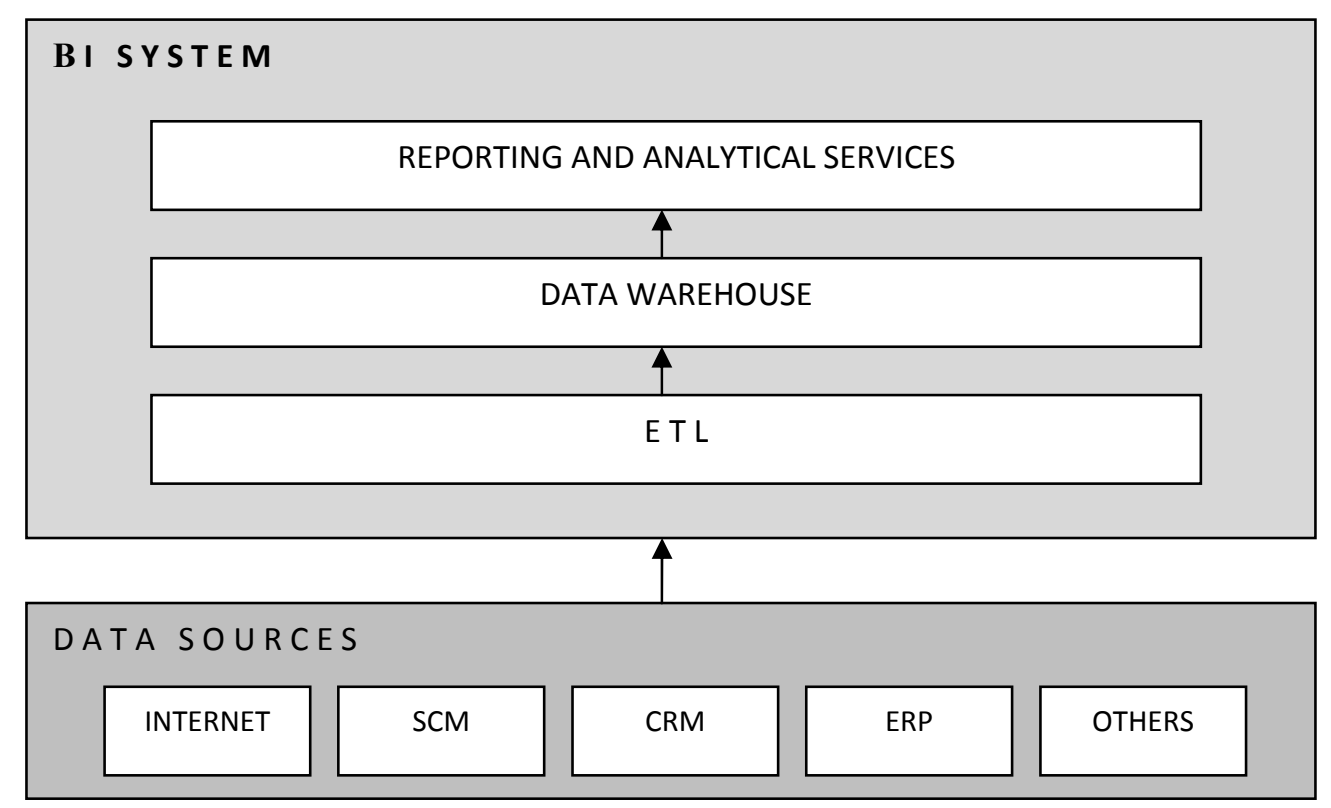

Figure 1. A simplified diagram of the BI system

The BI system helps in decision-making because it interferes in all stages of the process and simplifies them [9]. It stores data in one place (eliminating the problem of open access to data and its dispersion, as well as the existence of duplicates). It solves the problem of outdated information, enables a more accurate data analysis and data conversion into information. It is obvious that only a system that contains all the basic building blocks, listed in Figure 2, can actually support the decision-making process. Full and comprehensive BI systems are offered by corporations such as Microsoft, Oracle, IBM or SAP. The comprehensiveness of the systems offered by these companies is accompanied by a high price. Most small and mediumsized businesses have neither the resources nor the need for such expensive solutions. Nonetheless, it is possible to build a functional BI system, however small, out of components offered by smaller companies, to assist the decision-making process. Such a system, integrating the solution of several different suppliers, was used in the studied IT support organization.

\section{The characteristics of the studied company and its main problems}

The studied entity is a company called Avena Technologies, operating in the IT and telecommunications industries. It is involved in the construction and administration of the urban network in Darłowo (Poland) and it provides services to over 3000 customers. The company provides IT outsourcing services: the installation and administration of network infrastructure, the implementation and administration of VoIP telephony and a helpdesk. In addition, Avena assembles and maintains a wireless Internet service in Gdansk and Gdynia using Hot Spots. Moreover, the company is currently working on an intelligent traffic monitoring system. The project involves the installation of cameras along the Tri-city ring road, the preparation of appropriate software, which allows constant monitoring of traffic on the roads, and in particular, events such as traffic jams, accidents and road works, in order to make this information available round the clock for all Internet users.

Avena was founded 10 years ago, in 2003, and has since been developing dynamically. Currently, it has two offices in Poland, in Gdynia and Gdansk. The company provides external IT services to more than 30 companies in the Tri-city area. The majority of its employees in both locations work in the helpdesk department. Their remote technical support is innovative, and very few companies in Poland provide such a service, hence demand greatly exceeds supply (19 companies in Poland provide IT helpdesk services, none of which is located in the Tri-city) [10]. It was due to the significant workload in the helpdesk department that the company was forced to improve management. With thousands of service requests (SRs in short, this abbreviation will be used later in the paper), the company gradually lost the ability to control its own activities. It became impossible to manage customer data, monitor employee performance, analyze 
information and combine it in certain patterns. Moreover, the company had a problem with assessing the quantity of services and the management was not able to determine how much time was spent on customer service, how much it cost, and thus, whether cooperation with customers was remunerative.

Since 2010, when the company started providing helpdesk services, the management's ability to make rational decisions decreased significantly. Due to the nature of the services and the large number of requests, numerous problems appeared preventing or at least hindering the decision-making process. They included:

- excess of data in some areas (e.g. thousands of records related to SRs) and shortage of data in other areas (e.g. knowledge of the current state of the customer IT infrastructure),

- difficult and slow access to data (e.g. a customer makes an inquiry about the possibility of installing a newer operating system on all of their computers a manual check of hundreds of computers is very time consuming),

- scattered data (over hundreds of computers among dozens of clients),

- inaccuracies of data (without automatic updates on the state of the infrastructure, data must be obtained a new every time),

- inability to monitor own activities (which employees provided services to a given client, how long it took, how to measure their performance),

- problems with the aggregation of data and its transformation into specific information (e.g. due to clients using different hardware and software).

Decision-making in such conditions was associated with working in a state of high uncertainty, regardless of whether the problem existed on the side of the client or the support organization. The management realized that the company is not able to function effectively without the support of appropriate IT systems. To cope with the above-mentioned problems, the company decided to implement a BI system. This was done, however, without the conviction that the decision was in fact the correct one. The management had no premise to justify the planned expenditure. Moreover, the changes that took place in the organization after the deployment of the system were not evaluated. This task became the target of our research. The next chapter presents a method, which the authors have developed to determine the validity of implementing BI in Avena.

\section{$4 \quad$ Measuring the effects of implementing the BI system}

\subsection{Assumptions and key performance indicators}

Is it possible to measure the effects of implementing BI? For this purpose, it is necessary to create a number of evaluation indicators and then establish the changes in their values before and after the implementation of the BI system, preferably in similar periods of time. The scope of these indicators should cover the most part of the company's operation, not just one particular area. This is due to the fact that the BI system is meant to generally support decision-making in all aspects of business, and thus the indicators are designed to illustrate numerically as many of these aspects as possible.

Although companies are different, several indicators may be used for most of them. Of course, they can be closely matched to the characteristics of the studied organization, and some may arise precisely tailored to the specific organization. Examples of indicators include [11]:

- number of clients served/transactions executed/sales of goods, etc.,

- number and productivity of employees,

- actual working time of employees,

- task initiation-to-completion time,

- degree of customer satisfaction.

It should be noted that some of these indicators can be easily quantified (e.g. the number of transactions), while others are qualitative (e.g. customer satisfaction). The authors, however, set themselves a goal to make a quantitative evaluation. Therefore, it was necessary to use certain simplifications to determine the value of indicators for the evaluation. Naturally, it was also necessary to collect relevant data for comparing the periods before and after the implementation of the BI system. This was obviously much easier to do in reference to the period "after implementation" because the BI system allows the necessary information to be obtained.

To assess the validity of implementing BI at Avena, two periods were compared:

- the period between April 1, 2011 and September 30,2011 (P1),

- and a year later, namely the period between April 1, 2012 and September 30, 2012 (P2). 


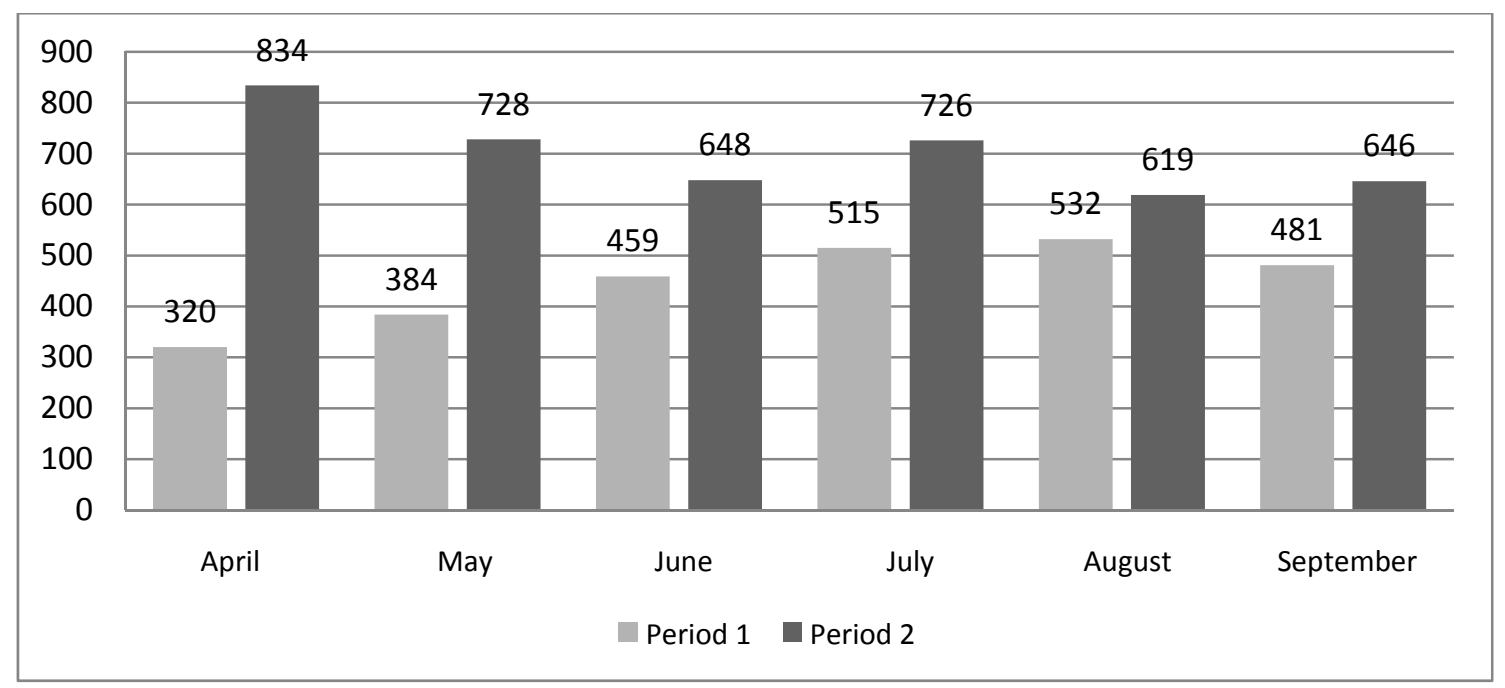

Figure 2. Number of SRs in P1 and P2

To describe the business, the following four aspects were selected:

- the number of SRs (Service Requests - understood as problems reported by users to an IT support organization), which require certain actions,

- the number of administrators and their effectiveness,

- mean time to repair (MTTR - the average time required to repair a damaged device; in this case, it is the estimated time in which the administrator is required to deal with a request from its opening to closure),

- the degree of customer satisfaction.

In the study, each of these aspects was described quantitatively and one or two indicators were developed for each aspect. It should be noted that the BI system was first launched in late March 2011, just before the start of P1.

\subsection{Comparison of the number of service requests (SRs)}

Within 6 months of P2, the organization processed 4201 SRs in total, which makes an average of 700 requests per month. There were 130 working days between April 1 and September 30, 2012, which gives a little more than 32 requests per day

$$
\mathrm{AVG} \frac{\mathrm{SR}}{\mathrm{DAY}}=\frac{4201}{130}=32.32
$$

Within P1, Avena processed fewer requests than in P2 - the number of completed SRs was 2691. There were
131 working days in period 1 , which allows the calculation of the average daily number of requests

$$
\mathrm{AVG} \frac{\mathrm{SR}}{\mathrm{DAY}}=\frac{2691}{131}=20.54
$$

This number of requests means that during P2, Avena handled far more SRs than the year before - making an increase of $56.11 \%$

$$
\frac{P 2}{P 1} * 100 \%=\frac{4201}{2691} * 100 \%=156.11 \%
$$

Of course, the number of requests, and thus - the average number of requests - it is not the only difference between the study periods. One quantitative value within the 6-month period is not yet conclusive. What is much more interesting is the distribution of the number of requests in given months, which is illustrated below in Figure 2.

As the chart presents, there is a significant difference between the values obtained in the month of April. During the first month after the implementation of the BI system, the studied organization processed less than half the amount of SRs than a year later. In the following months, this difference began to diminish. In August, it was relatively small and amounted to only $16.35 \%$. It is clearly visible that the company needed time to get used to the new system, although this certainly is not the only reason. Agent programs, used to operate the whole system and specifically for data collection, had to be installed on the computers of clients, which obviously took time. Similarly, the customers had to get used to the new request system. After a few months, the differences between P1 and P2 decreased significantly. 


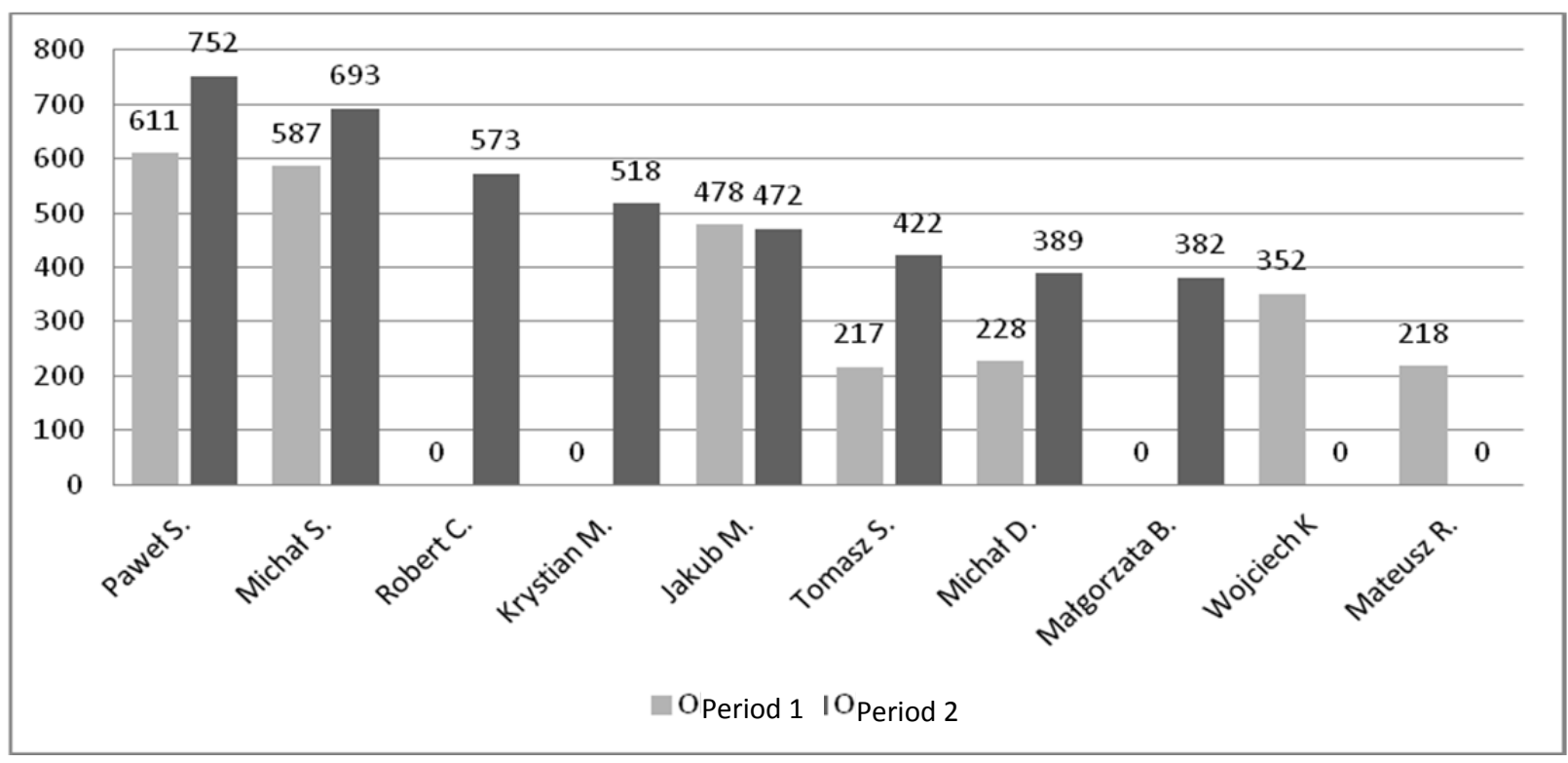

Figure 3. Comparison of the number of SRs closed by administrators

\subsection{Comparison of the number of administrators and their performance}

At the beginning of 2011, seven administrators were assigned to operate the SRs, which is one less than the following year. Five of the groups continue to work for the company. By April 2012, three new administrators were employed. Wherever possible, the number of SRs was compiled on the basis of both periods; in other cases, the amount of an administrator's SRs was shown in one period. The number of SRs closed by administrators in both periods is shown in Figure 3.

The graph shows that in four out of five cases, the administrators who stayed in the company responded to more calls in 2012 than the year before. In one case, the situation is the reverse, but the difference is insignificant (only six SRs, which corresponds to about a day of work). Naturally, one period cannot be compared with the other only on the basis of the five employees who continue working, and a wider view is needed. For this purpose, the average activity time (the actual recorded working time) for all employees in both periods was measured. The value was obtained by dividing the total time spent on tasks (the BI system stores such data) by the number of man-hours available during these periods. The results are shown in Table 1.

Table 1. Comparison of the average working times

\begin{tabular}{|c|c|c|c|c|c|}
\hline & \multicolumn{2}{|c|}{ Period $1(\mathrm{P} 1)$} & \multicolumn{2}{|c|}{ Period $2(\mathrm{P} 2)$} & \multirow[b]{2}{*}{$\begin{array}{l}\text { Difference } \\
\text { P2-P1 }\end{array}$} \\
\hline Administrator & $\begin{array}{c}\text { Task } \\
\text { duration time } \\
(\mathrm{h}: \mathrm{m})\end{array}$ & $\begin{array}{l}\text { Average daily } \\
\text { working time } \\
\text { (h) }\end{array}$ & $\begin{array}{c}\text { Task } \\
\text { duration time } \\
(\mathrm{h}: \mathrm{m})\end{array}$ & $\begin{array}{l}\text { Average daily } \\
\text { working time } \\
\text { (h) }\end{array}$ & \\
\hline Paweł S. & 651 & 4.97 & 794:00 & 6.11 & 1.14 \\
\hline Michał S & 678 & 5.18 & 728:00 & 5.60 & 0.42 \\
\hline Robert C. & - & - & $414: 45$ & 3.19 & 3.19 \\
\hline Krystian M. & - & - & $877: 45$ & 6.75 & 6.75 \\
\hline Jakub M. & 569 & 4.34 & 749:30 & 5.77 & 1.43 \\
\hline Tomasz S. & $472: 30$ & 3.61 & $312: 45$ & 2.41 & -1.2 \\
\hline Michał D. & 602 & 4.60 & $738: 30$ & 5.68 & 1.08 \\
\hline Małgorzata B. & - & - & $479: 15$ & 3.69 & 3.69 \\
\hline Wojciech K. & 341 & 2.60 & - & - & -2.6 \\
\hline Mateusz R. & $267: 45$ & 2.04 & - & - & -2.04 \\
\hline & & 3.9 & & 4.9 & \\
\hline
\end{tabular}


Table 2. Performance indicator $\Delta \mathrm{SR}-\Delta t$

\begin{tabular}{|c|c|c|c|c|c|c|c|}
\hline Admin. & $\begin{array}{l}\text { Avr. } t . \mathrm{P} 1 \\
\text { (h) }\end{array}$ & $\begin{array}{l}\text { Avr. } t . \mathrm{P} 2 \\
\text { (h) }\end{array}$ & $\Delta t$ & $\begin{array}{l}\text { SR } \\
\text { P1 }\end{array}$ & SR P2 & $\Delta \mathrm{SR}$ & $\begin{array}{c}\text { Performance } \Delta \\
\text { SR }-\Delta t\end{array}$ \\
\hline Paweł S. & 4.97 & 6.11 & $22.94 \%$ & 611 & 752 & $23.08 \%$ & $0.14 \%$ \\
\hline Michał S. & 5.18 & 5.60 & $8.11 \%$ & 587 & 693 & $18.06 \%$ & $9.95 \%$ \\
\hline Jakub M. & 4.34 & 5.77 & $32.95 \%$ & 478 & 472 & $-1.26 \%$ & $-34.20 \%$ \\
\hline Tomasz S. & 3.61 & 2.41 & $-33.24 \%$ & 217 & 422 & $94.47 \%$ & $127.71 \%$ \\
\hline Michał D. & 4.60 & 5.68 & $23.48 \%$ & 228 & 389 & $70.61 \%$ & $47.14 \%$ \\
\hline & & & $10.85 \%$ & & & $40.99 \%$ & $30.15 \%$ \\
\hline
\end{tabular}

By combining data on the average daily working time during in the two periods, it could be easily determined which employees were improving and which were not. It is also worth noting that in P1, two employees had a particularly low daily working time (a little over $2 \mathrm{~h}$ per day). In effect, it was these employees who were dismissed. It can thus be concluded that employees spent more time solving problems in P2 than in P1. It is unsurprising, given that the number of SRs increased. Therefore, another table should be added to the analysis, one which compares several indicators simultaneously: the number of closed SRs, the average daily working time, the number of SRs per hour and the increase in these values in percentages. Such a comparison table is only relevant for those employees who worked in both periods.

Table 2 illustrates the changes in employee performance in the two periods. First of all, it compiles the time needed to close the SR and shows whether the administrator worked more or less. The $\Delta t$ indicator itself does not say, however, whether this is good or bad - after all, an employee may work less and be more efficient. To calculate such performance, the next three columns compare the changes in the number of problems solved $(\Delta \mathrm{SR})$. The last and most important column is the indicator of employee efficiency. It summarizes the difference in the time needed to complete a task and the change in the number of closed SRs. This helps to determine the growth in the administrator's performance. If the value in this column is 0 , it means that the increase in the average working time is directly proportional to the increase in the number of SRs. If the value is positive, the administrator uses his time efficiently, if negative - less efficiently. The table shows that four-fifths of administrators increased their efficiency a year after the implementation of BI.

\subsection{The comparison of mean time to repair (MTTR)}

The parameter of MTTR is the average time, which is needed to repair the device after failure [12]. This time is often specified in a contract and can determine whether a company dedicated to maintenance (in this case, the studied company meant to address issues related to IT) fulfills its obligations as expected (i.e. the SLA - Service Level Agreement). The same is true in this case - customers expect that their problems will be resolved within the specified time. If such time is not indicated by the SLA, the manager decides what the MTTR is for a particular task while allocating tasks. After the problem is resolved, the request must first be verified and then closed. The average closure time, verification time and MTTR in P1 were studied to establish whether the company met its obligations in the required time. In P2, in four out of six cases the MTTR was exceeded. Table 3 presents the comparison of these values with $P 1$.

As it transpires, in every month within P1, Avena managed to fit into the required task closure and verification time. In April 2011, the company had a significant time margin of over 1100 man-hours. The management realized that a lot of time was wasted and gradually reduced the MTTR. Similarly, clients came to the conclusion that the time they had allocated to such services was overestimated and they reduced it too. Nonetheless, in P1, the MTTR remained too high and the company had an excess of time. In P2, the situation was reversed: the company did not keep up with the work. If Avena signed an SLA in P1, it would have no problems with respecting the provisions of the agreement. In $\mathrm{P} 2$ it is impossible. 
Table 3. MTTR compared with the closure time and the verification time of SRs in P1

\begin{tabular}{|c|c|c|c|c|c|c|}
\cline { 2 - 7 } \multicolumn{2}{c|}{} & \multicolumn{3}{|c|}{ Period 1 } & \multicolumn{3}{c|}{ Period 2 } \\
\hline Month & $\begin{array}{c}\text { MTTR } \\
(\mathrm{h})\end{array}$ & $\begin{array}{c}\text { Closure time } \\
\text { and verifica- } \\
\text { tion time (h) }\end{array}$ & Difference & $\begin{array}{c}\text { MTTR } \\
(\mathrm{h})\end{array}$ & $\begin{array}{c}\text { Closure time } \\
\text { and verifica- } \\
\text { tion time (h) }\end{array}$ & $\begin{array}{c}\text { Difference } \\
\text { April }\end{array}$ \\
\hline May & 1594.8 & 481.25 & 1113.55 & 1320.20 & 1010.05 & 310.15 \\
\hline June & 1407.2 & 558.75 & 848.45 & 1161.10 & 1188.42 & -27.32 \\
\hline July & 775.4 & 585.75 & 189.65 & 868.80 & 1144.25 & 28.1 \\
\hline August & 1394 & 702 & 692 & 756.60 & 1015.75 & -275.45 \\
\hline September & 1144.5 & 627 & 517.5 & 797.90 & 1093.25 & -259.15 \\
\hline & $\mathbf{7 3 2 1 . 2}$ & $\mathbf{3 6 6 9 . 5}$ & $\mathbf{3 6 5 1 . 7}$ & $\mathbf{5 7 6 7 . 7 0}$ & $\mathbf{6 2 8 6 . 7 2}$ & $\mathbf{- 5 1 9 . 0 2}$ \\
\hline
\end{tabular}

In a theoretically ideal situation, the MTTR should be equal to or greater than the times of closure and verification. Naturally, the smaller the difference between those times, the more effective the use of working time is. The time required for closure and verification should amount to about $90-95 \%$ of the MTTR, so that in the event of an emergency, there would be a certain time margin. Excluding such a time margin, the upper limit may be set at $100 \%$ (i.e. the time of closure and verifi- cation of SRs is exactly the same as the MTTR). Table 4 shows the value of the quotient of the closure and verification time and the MTTR.

As shown in Table 4, in seven of the researched months the value of the closure time and verification time/MTTR is too low; in four months, it is too high, and only in one it is appropriate (June 2012). The Table is complemented by Figure 4.

Table 4. Indicator of the closure and verification time/MTTR

\begin{tabular}{|c|c|c|c|c|c|c|}
\cline { 2 - 7 } \multicolumn{2}{c|}{} & \multicolumn{4}{|c|}{ Period 1 } & \multicolumn{3}{c|}{ Period 2 } \\
\hline Month & $\begin{array}{c}\text { MTTR } \\
(\mathrm{h})\end{array}$ & $\begin{array}{c}\text { Closure time } \\
\text { and verifica- } \\
\text { tion time (h) }\end{array}$ & $\begin{array}{c}\text { Closure } \\
\text { time and } \\
\text { verification } \\
\text { time/MTTR }\end{array}$ & $\begin{array}{c}\text { MTTR } \\
\text { (h) }\end{array}$ & $\begin{array}{c}\text { Closure time } \\
\text { and verifica- } \\
\text { tion time (h) }\end{array}$ & $\begin{array}{c}\text { Closure time } \\
\text { and verifica- } \\
\text { tion } \\
\text { time/MTTR }\end{array}$ \\
\hline April & 1594.8 & 481.25 & $30.18 \%$ & 1320.20 & 1010.05 & $76.51 \%$ \\
\hline May & 1407.2 & 558.75 & $39.71 \%$ & 1161.10 & 1188.42 & $102.35 \%$ \\
\hline June & 1005.3 & 714.75 & $71.10 \%$ & 863.10 & 835.00 & $96.74 \%$ \\
\hline July & 775.4 & 585.75 & $75.54 \%$ & 868.80 & 1144.25 & $131.70 \%$ \\
\hline August & 1394 & 702 & $50.36 \%$ & 756.60 & 1015.75 & $134.25 \%$ \\
\hline September & 1144.5 & 627 & $54.78 \%$ & 797.90 & 1093.25 & $137.02 \%$ \\
\hline
\end{tabular}




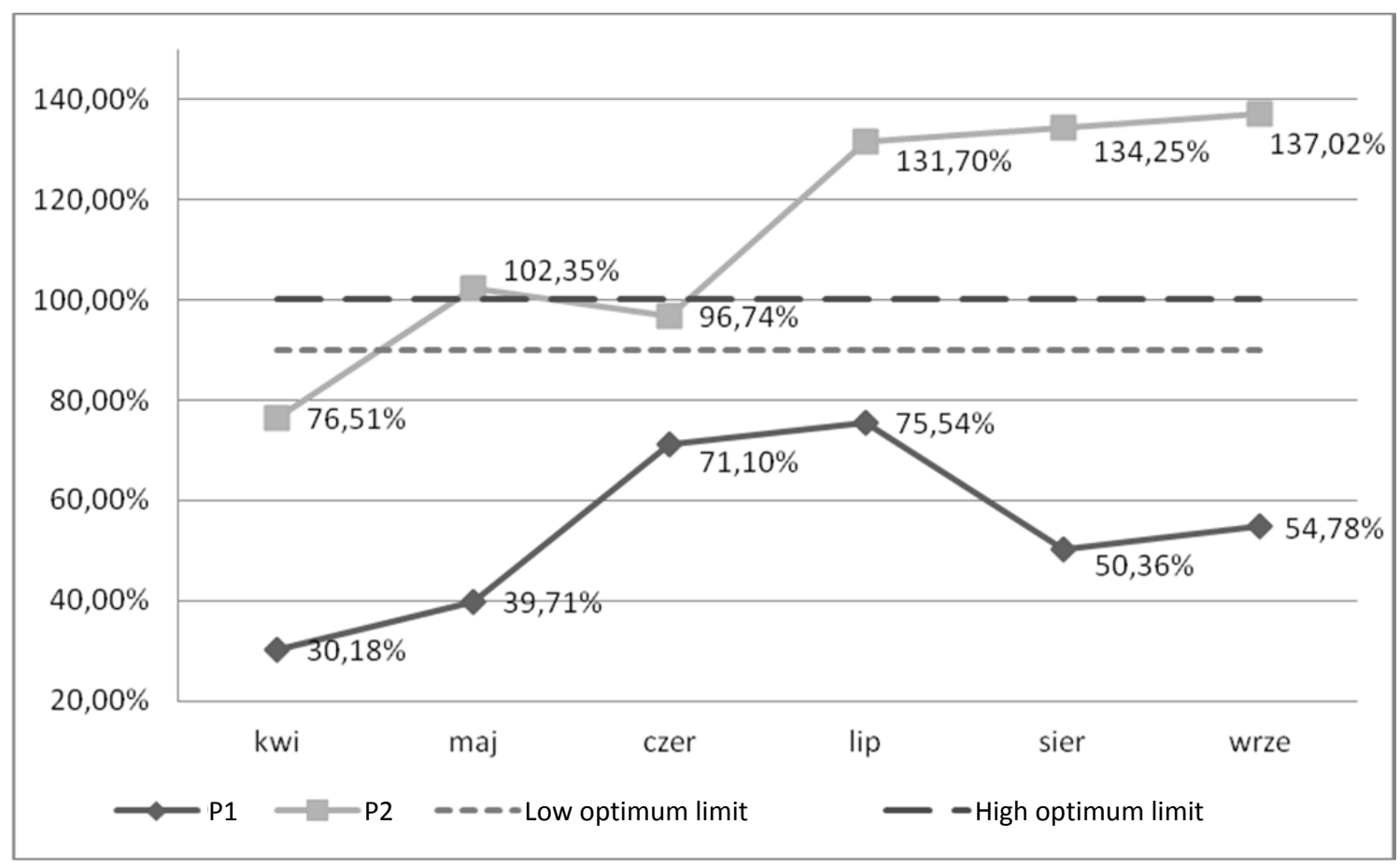

Figure 4. Indicator of the closure and verification time/MTTR in periods P1 and P2

The graph shows clearly how much the values of the closure and verification time/MTTR deviate from the norm. The values of the indicator for both P1 and P2 periods should be between the lower and the upper limit - then the value of the indicator would be optimal. Two trends can be observed in both periods: in $\mathrm{P} 1$, the closure and verification time/MTTR was generally too low, and in P2 - it was generally too high.

\subsection{The comparison of firms to which services were provided and the ratio of open SRs to closed SRs}

The increase in the number of SRs in P2 in relation to $\mathrm{P} 1$ is not accidental. Between these periods, the company gained new clients, without losing any. In P1, the number of clients was 29, in P2 it was 36. Among the top 10 largest clients, seven of them reported more than 100 requests, others reported fewer. Interestingly, the eight largest clients in P1, remained in P2 in the top 10 most important clients for Avena. It is very important that, despite some shortcomings in the company's operation (which were mentioned before), the clients continued to use the services of Avena (Table 5).

On average, each client-company reported $100 \%$ more SRs than in P2 than in P1 (which does not necessarily mean that the total number of requests between P1 and P2 also doubled). Although this value is positive for Avena, the authors indicated to the management the appearance of extremes in specific data. Some companies almost ceased to use the services of Avena (Why? Has the contract expired or are the clients dissatisfied with the services?). It can be said that the change in the number of requests reported by each of the companies is an indicator of satisfaction with the services provided by the researched organization.

Table 5. The change in each clients' open requests

\begin{tabular}{|c|c|c|c|}
\hline Open SRs in P1 & Open SRs in P2 & $\Delta \mathrm{OSRC}$ & \\
\hline 2691 & 4201 & $100.81 \%$ & For all clients \\
\hline 2691 & 3759 & $99.32 \%$ & Excluding new clients \\
\hline
\end{tabular}


Table 6. Values of the evaluation indicators

\begin{tabular}{|c|c|c|c|c|c|}
\hline Item & Indicator & $\begin{array}{l}\text { Indicator } \\
\text { acronym }\end{array}$ & $\begin{array}{c}\text { Type } \\
\text { of indicator }\end{array}$ & Value & Norm/comment \\
\hline 1 & $\begin{array}{c}\text { Change in the number of } \\
\text { SRs }\end{array}$ & $\Delta \mathrm{SR}$ & Direction & + & No higher limit \\
\hline 2 & $\begin{array}{l}\text { Change in the average } \\
\text { daily working time } \\
\text { of an administrator }\end{array}$ & $\triangle \mathrm{AAT}$ & Direction & $+1 \mathrm{~h}$ & No higher limit \\
\hline 3 & $\begin{array}{l}\text { Value of the average dai- } \\
\text { ly working time } \\
\text { of an administrator }\end{array}$ & AAT & Value & $4.9 \mathrm{~h}$ & $0-8$ \\
\hline 4 & $\begin{array}{l}\text { Performance of the ad- } \\
\text { ministrators who worked } \\
\text { in both periods }\end{array}$ & $\Delta \mathrm{SR}-\Delta \mathrm{t}$ & Direction & $+30.15 \%$ & No higher limit \\
\hline 5 & $\begin{array}{l}\text { Value of the ratio } \\
\text { between the closure time } \\
\text { and verification time } \\
\text { and the MTTR }\end{array}$ & $\begin{array}{l}\text { Closure time } \\
\text { and } \\
\text { verification } \\
\text { time/MTTR }\end{array}$ & Value & $113.10 \%$ & $90-100 \%$ \\
\hline 6 & $\begin{array}{l}\text { Change in the number } \\
\text { of clients }\end{array}$ & $\Delta$ Client & Direction & $+24.13 \%$ & No higher limit \\
\hline 7 & $\begin{array}{l}\text { Change in the difference } \\
\text { between open and closed } \\
\text { requests }\end{array}$ & $\Delta \mathrm{O}-\Delta \mathrm{C}$ & Value & -19 & 0 \\
\hline 8 & Client retention & $\% \mathrm{SRC}$ & Value & $45 \%$ & $75-100 \%$ \\
\hline
\end{tabular}

According to a normal schedule, if company $\mathrm{X}$ reported a number $n$ of SRs in one period, in the same period in the following year it should report roughly the same $n$ amount (this assumption does not take into account significant changes that may occur in the company a significant drop in value, mass layoffs, the construction of new premises and the employment of new workers, etc., which could obviously significantly affect the number of requests). Naturally, the increase or decrease in the number of requests may depend on random events. The likelihood of such events is, unfortunately, impossible to estimate, although it can be assumed that there is the same chance for a random occurrence of both negative and positive events. Therefore, the impact of random events was omitted from this analysis.

\section{The evaluation of the performance of the BI system implementation}

The interviews conducted by the authors show that at some stage of the company's development, the man- agement of Avena was no longer able to make the right decisions. That is why in early 2011 BI was implemented. Between the study periods, the organization changed under the influence of actions resulting from the conclusions drawn from the data collected and analyzed by the BI system (at least in part). Although the various individual decisions are unknown, their impact can be measured by several parameters. Thanks to the prepared indicators (described earlier), it can be evaluated whether the implementation of the BI system was justified and if, on the basis of the obtained information, the company made decisions that increased its efficiency.

The authors chose eight indicators, which belong to either one of these two categories:

- Direction indicators - They indicate the direction of the changes, which take place, their greatest significance is not their value but their symbol.

- Value indicators - In their case what matters most is the number itself, which should fit within a certain range. The range was designated subjectively by the authors. 
All the indicators have been compiled in Table 6, including the calculated values and suggested norms for each of them. It is important to briefly comment on and justify the value of each of the indicators, assessing its nature (positive/negative).

Each value has been evaluated by the authors on a scale of 1-5. A brief explanation as to why the indicator received such an evaluation is presented in the column "comments". The evaluation of the BI system implementation and of the effects of actions undertaken by Avena will take the form of an arithmetic mean of the individual indicators.

Finally, the effectiveness of the change that Avena underwent has been evaluated at $72.6 \%$. The following evaluation brackets have been assumed (in percentages):

- $<0.50>\Rightarrow$ unsatisfactory

values below $50 \%$ mean that the changes do not bring any positive effects, not even small ones,

- (50.65) $\Rightarrow$ satisfactory the changes are small but positive,

- $<65.80) \Rightarrow$ good the changes are rather positive, although not all the solutions are adequately developed,

- $<80.100>\Rightarrow$ very good

the changes are clearly positive, few elements require improvement.

Based on this scale, it can be stated that the result of $72.6 \%$ is good enough to say that the implementation of the BI system was profitable. At the same time, it was made evident which areas of the company's operation are not working efficiently enough. On the basis of analyses and comparisons, as well as the authors' knowledge about the company, a few appropriate and inappropriate decisions taken by the management can be pointed out. It is also possible to indicate some appropriate decisions, which were made for good reasons and which turned out to be not quite right due to changes in certain factors:

- It was possible to determine which employees worked ineffectively. They were dismissed and replaced by others who work more effectively. $\Rightarrow$ The right decision.

- Thanks to grouping incidents, it was possible to define certain recurrent problems. The company introduced the so-called SIP policy. If a problem recurs, an employee (usually from the management) is asked to create an SIP, namely an article that ends up in the knowledge base and that describes stepby-step how to solve the problem. In effect, the performance of employees increases and a greater number of requests can be processed by an administrator.

$\Rightarrow$ The right decision.

- The MTTR was reduced. It was discovered that the MTTR in P1 was underestimated, which meant that employees had too much time to complete a task; thus, the expected closure and verification time of SRs was reduced. Because employees had an excess of time, it was possible to sign contracts with a greater number of clients, which was to help use the working time more effectively.

Unfortunately, the current clients also concluded that the problems they addressed to Avena can be resolved quicker and they too reduced the MTTR. In result, Avena provides services to too many clients with respect to its capabilities and it exceeds the MTTR. The decision to reduce the MTTR was, therefore, right in $\mathrm{P} 1$; however, due to the change in external factors, it brings negative results in $\mathrm{P} 2$.

$\Rightarrow$ The decision was right to a degree.

In conclusion, it can be stated that the evaluation of the effectiveness of the BI system implementation at $72 \%$ is justified. Thanks to this investment, the company managed to detect some problems and, by taking decisions based on specific information, respond to them. It is clear that the company has developed significantly since the beginning of the implementation process in P1 until the end of P2. However, the rapid development brought new problems, which the company must now face. Avena is not yet able to use the full capacity of the system, which it possesses - the management overlooked a few cases in which a problem should have been detected and dealt with - for example, the employment of one or two administrators could have solved the problem of exceeding the MTTR and would have thus reduced customer dissatisfaction. Nonetheless, despite some imperfections in the functioning of the organization, the decisions taken by the management of Avena proved to be accurate in most cases.

It should be noted that the evaluation of the decision to implement the BI system was based on the assumption that other than the implementation of the BI system, nothing else changed in the studied organization. Naturally, this assumption is not entirely correct as every organization changes over time. 
Table 7. Indicator value evaluation

\begin{tabular}{|c|c|c|}
\hline Indicator & Comment & Evaluation \\
\hline$\Delta \mathrm{SR}$ & $\begin{array}{l}\text { A } 56 \% \text { increase in the number of requests in a year signifies the great pace } \\
\text { of the company's development }\end{array}$ & 5 \\
\hline$\triangle \mathrm{AAT}$ & $\begin{array}{l}\text { A } 1-\mathrm{h} \text { (or } 25.64 \%) \text { increase signifies that the administrators indeed work } \\
1 \mathrm{~h} \text { longer a day. } \\
\text { It is a change in a good direction, provided that the AAT is not exceeded }\end{array}$ & 5 \\
\hline AAT & $\begin{array}{l}\text { The average daily working time of the administrators is } 4.9 \mathrm{~h} \text {. } \\
\text { Assuming that a working day is } 8 \text {-h long, } 4.9 \mathrm{~h} \text { makes only } 61.25 \% \\
\text { of a working day. } \\
\text { The value of the indicator is much too low; the administrators do not use their } \\
\text { working time in full }\end{array}$ & 2 \\
\hline$\Delta \mathrm{SR}-\Delta \mathrm{t}$ & $\begin{array}{l}\text { The value of the } \Delta \mathrm{SR}-\Delta t \text { indicator at } 30.15 \% \text { signifies that the administrators } \\
\text { who worked in the company in } \mathrm{P} 1 \text { and } \mathrm{P} 2 \text { disproportionately increased } \\
\text { their performance by } 30 \% \text { when compared with the expected value. } \\
\text { This is a lot }\end{array}$ & 5 \\
\hline $\begin{array}{l}\text { Closure time } \\
\text { and verifica- } \\
\text { tion } \\
\text { time/MTTR }\end{array}$ & $\begin{array}{l}\text { The value of the closure time and verification time/MTTR indicator at } 113.10 \% \\
\text { signifies that the company does not fit into the designated SR times. } \\
\text { On the other hand, the MTTR was evidently underestimated in P1. } \\
\text { Adjusting the MTTR is a positive change, however, not with such a number } \\
\text { of SRs. } \\
\text { Avena is not capable of keeping the rigorous MTTR defined in the SLA }\end{array}$ & 2 \\
\hline$\Delta$ Client & $\begin{array}{l}\text { With only one additional employee, Avena managed to provide services to } 24.13 \% \\
\text { more clients in P2 than P1. } \\
\text { This is a significant increase }\end{array}$ & 5 \\
\hline$\Delta \mathrm{O}-\Delta \mathrm{C}$ & $\begin{array}{l}\text { In } \mathrm{P} 2 \text {, the company closed } 19 \text { requests more than it opened which means that it was } \\
\text { forced to close and verify overdue requests. } \\
\text { On the other hand, the value of } 38 \text { in P1 meant that work was done too slowly } \\
\text { and the tasks were spread over too much time. } \\
\text { The direction of the changes is positive but the value of the indicator continues } \\
\text { to be incorrect }\end{array}$ & 3 \\
\hline$\% \mathrm{SRC}$ & $\begin{array}{l}\text { More than half }(55 \%) \text { of clients delivered less requests in P2 than in P1. } \\
\text { This could result from the clients' situation or the level of the service provided. } \\
\text { Although most companies use Avena's services to a smaller degree, no client } \\
\text { ceased cooperation. } \\
\text { It is necessary to study the extremes and establish the causes } \\
\text { of the present phenomenon }\end{array}$ & 2 \\
\hline & & $\begin{array}{l}\text { Evaluation: } \\
\begin{array}{l}3.63 \\
(72.6 \%)\end{array}\end{array}$ \\
\hline
\end{tabular}


The analyses were based entirely on the specific numerical values from the corresponding tables of the database. However, not everything that changes in a company is recorded in those tables. For example, the increase in an employee's efficiency is partly the result of the introduced methods, and partly due to the person's increased experience.

The same could be said of other indicators. Unfortunately, it is impossible to quantitatively evaluate the impact of factors, which are intrinsically irrational. For this reason, it was assumed that only data that can be expressed in numbers would be taken into account, and that any changes in the company result from the implementation of the BI system. With this assumption in mind, it can be stated that the application of the BI system led to the reduction of problems associated with decision-making and resulted in an improvement in this area, which positively affected the work of the entire organization.

\section{Summary}

This paper presents a method for evaluating the implementation of information technology called a Business Intelligence system in an IT organization. Due to expanding the scope of its business, the studied organization of IT support faced a number of new problems, which it was unable to cope with without the help of an IT system. The system was implemented, yet without any prior analyses of the potential effects of such change.

The authors carried out such analyses by comparing data available for two periods of time. This gave the opportunity to determine in which aspects of its operation the company gained and in which it lost. It transpired that the company's undoubted success was the increase in the number of processed SRs by more than half, and increasing employee productivity by $20-30 \%$ via observations, standardization and the creation of knowledge bases. Avena now provides services to $24 \%$ more clients than before.

These improvements are the result of appropriate decision-making, which has been made possible through the use of Business Intelligence tools. A few risks were noticed: exceeding the accepted MTTR or establishing cooperation with too many clients with respect to the company's potential.

It should be noted that the evaluation of the decision to implement the BI system was based on the assump- tion that apart from the implementation of the BI system, nothing else changed in the company. Naturally, this assumption is not entirely correct as every organization changes over time.

The analyses were based entirely on the specific numerical values from the corresponding tables of the database. However, not everything that changes in a company is recorded in those tables. For this reason, it was assumed that only data that can be expressed in numbers would be taken into account, and that any changes in the company result from the implementation of the BI system. With this assumption in mind, it can be stated that the application of the BI system led to the reduction of problems associated with decision-making and resulted in an improvement in this area, which positively affected the work of the entire organization.

The authors' current goal is to verify the model for other support organizations, and for technologies other than Business Intelligence .

\section{$7 \quad$ Bibliography}

[1] Samuelson W.F., Marks S.G. - Ekonomia menedżerska (Managerials Economics). PWE, Warszawa 1998.

[2] Targalski J. - Podejmowanie decyzji (Decisionmaking) [in] Organizacja i zarządzanie (ed. Stabryła A., Trzcieniecki J.). Warszawa 1986.

[3] Griffin R.W. - Podstawy Zarzqdzania Organizacjami (Fundamentals of Management Organizations). PWN, Warszawa 1998.

[4] Radosiński E. - Systemy informatyczne $w$ dynamicznej analizie decyzyjnej (Systems in dynamicanalysis of decision-making). PWN, WarszawaWrocław 2001.

[5] Alter S. - Systems: a management perspective., Addison Wesley Longman, 1999.

[6] Januszewski A. - Funkcjonalność informatycznych systemów zarzqdzania (The functionality of a IT systems). Tom 2 System Business Intelligence. Wydawnictwo Naukowe PWN, Warszawa 2008.

[7] Gartner home page, http://www.gartner.com (accessed on 2012.11.05).

[8] Quarles van Ufford D. - Business Intelligence. The Umbrella Term. BWI-Werkstut, Amsterdam, 2002. 
[9] Orłowski C., Sitek T. - Supporting Management Decisions with Intelligent Mechanisms of Obtaining and Processing Knowledge [in] KnowledgeBased and Intelligent Information and Engineering Systems (ed. Setchi R.,, Jordanov I.,Howlett R.J., Jain L.C.). Springer-Verlag, Berlin Heidelberg 2010.

[10] Panorama Firm, http://panoramafirm.pl/szukaj?k=Helpdesk\&l=trój miasto, (accessed on 2012.11.16).
[11] Litka M. - Analiza decyzji o wdrożeniu systemu Business Intelligence $w$ organizacji wsparcia IT projekt modelu ocenowego (Analysis of the decision to implement a Business Intelligence system in ITSupport Organization - the idea of evaluation model). Wydział Zarządzania i Ekonomii, Politechnika Gdańska, Gdańsk 2012.

[12] Stanley S. - MTBF, MTTR, MTTF \& FIT - Explanation of Terms.IMC Networks, Foothill Ranch, 2011. 